\title{
Protocol Referenced Documents
}

National Cancer Institute

\section{Source}

National Cancer Institute. Protocol Referenced Documents. NCI Thesaurus. Code C142650.

A citation to a publication that is significantly related to a study protocol. 